\title{
Article \\ Factors Associated with Four Sexual Behaviors among Married/Partnered Women Ages 60 and Older in the United States
}

\author{
Caroline D. Bergeron 1,2 (D), Heather H. Goltz ${ }^{3}$ (D), Ali Boolani ${ }^{4,5, *(\mathbb{D})}$ and Matthew Lee Smith ${ }^{2,6}$ (D) \\ 1 LIFE Research Institute, University of Ottawa, Ottawa, ON K1N 6N5, Canada; caroline@bergeron.ca \\ 2 Center for Population Health and Aging, Texas A\&M University, College Station, TX 77843, USA; \\ matthew.smith@tamu.edu \\ 3 College of Public Service, University of Houston-Downtown, Houston, TX 77002, USA; goltzh@uhd.edu \\ 4 Department of Physical Therapy, Clarkson University, Potsdam, NY 13699, USA \\ 5 Department of Biology, Clarkson University, Potsdam, NY 13699, USA \\ 6 Department of Environmental and Occupational Health, School of Public Health, Texas A\&M University, \\ College Station, TX 77843, USA \\ * Correspondence: aboolani@clarkson.edu
}

check for

updates

Citation: Bergeron, C.D.; Goltz, H.H.; Boolani, A.; Smith, M.L. Factors Associated with Four Sexual Behaviors among Married/Partnered Women Ages 60 and Older in the United States. Sexes 2021, 2, 445-451. https://doi.org/10.3390/sexes2040035

Received: 3 September 2021

Accepted: 15 October 2021

Published: 18 October 2021

Publisher's Note: MDPI stays neutral with regard to jurisdictional claims in published maps and institutional affiliations.

\section{Copyright: (c) 2021 by the authors.} Licensee MDPI, Basel, Switzerland. This article is an open access article distributed under the terms and conditions of the Creative Commons Attribution (CC BY) license (https:// creativecommons.org/licenses/by/ $4.0 /)$.

\begin{abstract}
Women ages 60 and older vary in sexual behaviors. This study examined the prevalence of vaginal intercourse, outercourse, and receipt and performance of oral sex reported among 461 married/partnered women age $\geq 60$ years in the United States and factors associated with these four sexual behaviors. Using data from the National Social Life, Health, and Aging Project, associations between participants' socio-demographics, health indicators, sexual perceptions, communication, and sexual behaviors were examined. In the past year, 53.6\% reported having vaginal intercourse, $56.0 \%$ outercourse, and $21.7 \%$ receiving and $20.6 \%$ performing oral sex. Women with depressive symptomology were less likely to report intercourse and outercourse $(p<0.05)$. Women endorsing pleasurable sex as necessary to maintain relationships were more likely to report all four behaviors $(p<0.01)$. Women who communicated openly with partners were more likely to report intercourse $(p=0.002)$, outercourse $(p=0.001)$, and performing oral sex $(p=0.025)$. Findings may inform strategies about positive sex perceptions and strengthening partner communication.
\end{abstract}

Keywords: sexual health; older women; communication

\section{Introduction}

In the 1990s, changing sociocultural norms and medical and technological advances stimulated innovations in clinical practice and research about older adult sexuality and sexual health [1-3]. Recent research about older adult sexuality in the United States (U.S.) reveals a rich diversity in abilities, identities, experiences, lifestyles, and behaviors. These findings refute previously accepted myths and misconceptions of abstinence, asexuality, and inevitable age-related declines.

Frequently targeted by sexual ageism [4], many women report sexual interest, quality, and activity into oldest age [1-3]. At age 55, women have approximately 11 more years of sexually active life expectancy, which increases by roughly $50 \%$ among those reporting very good/excellent health [2]. In one U.S. population-based study, $17 \%$ of women aged 60-69 years reported mutual masturbation, while roughly $25 \%$ reported receiving oral sex from a partner in the previous year [1]. In another U.S. population study, approximately $40 \%$ of women ages $65-74$ years [2], and $17 \%$ of those $75+$ years, reported sexual activity within the previous year [1]. Roughly $60 \%$ of these women reported experiencing positive physical and emotional quality in their sexual lives [2]. In Liu, Shen, and Hsieh's 2019 study [5], more than one-third of older U.S. couples engaged in oral sex in the past year and associated receiving oral sex with relationship quality and emotional closeness. 
Although empirical studies about the sexual health experiences of older women of color are relatively limited, a 2010 study by Dodge and colleagues [6] revealed that very few older Hispanic women engaged in partnered masturbation or received oral sex from their partner; rather, they engaged in giving oral sex and vaginal intercourse. A recent study of the sexual experiences of African American women up to the age of 92 [7] revealed that older black women engaged in several sexual behaviors including receiving and giving oral sex, and vaginal intercourse during their most recent partnered sexual event [7]. While about half of women ages 70 years and older rated their experience as extremely pleasurable, another $30 \%$ found their experience to be of little or no pleasure [7].

While sex is an integral and important part of a relationship in older adulthood, pleasurable sex helps to increase the relationship's intimacy level [8] and is used to maintain a healthy long-term committed relationship [9]. To enhance a couple's emotional and sexual intimacy, general communication is needed between partners [10-12]. In fact, positive and open communication about vulnerabilities and worries is generally associated with greater intimacy between partners, while poorer communication patterns may make it more difficult for partners to feel close to each other [11].

Studies that intersect age (older 60+), gender (female), race/ethnicity (White, Hispanic, African American), and relationship status (married or partnered) are warranted to better understand the sexual health needs and experiences of this growing older adult population. Given this need, the current study aimed to address the following research question: what factors are associated with sexual behaviors among women ages 60 and older in married or long-term partnered relationships in the United States?

\section{Theoretical Framework}

Existing models of female sexual response have focused on physiological response and sexual behavior exclusively, with the exception of one developed by Rosemary Basson [13]. This more holistic model includes psychological, emotional, and relational factors such as communication, vulnerability, and pleasure/intimacy that influence women's sexual response and satisfaction, as well as more traditional indicators such as sexual behaviors. The present study was not designed to test the Basson model; however, the researchers employed an understanding of this model in interpreting study results.

\section{Materials and Methods}

\subsection{Participants and Procedures}

Data were analyzed from the National Social Life, Health, and Aging Project (NSHAP), a U.S. nationally representative probability survey of men and women ages 57-85 years [14]. NSHAP collects interview, survey, and biomarker data from older adults about topics including physical and mental health, healthcare utilization, social supports, and sexual health behaviors. This cross-sectional study examined secondary data from 'leave-behind' surveys to meet study aims. After applying inclusion criteria and omitting additional incomplete cases, the final analytic sample included 461 women, age $\geq 60$ years, who were married or lived with their partner. This study was considered as being non-human subjects research by the Texas A\&M University Institutional Review Board (\#20100417).

\subsection{Measures}

\subsubsection{Dependent Variables}

Primary outcomes of interest were four self-reported sexual behaviors: vaginal intercourse; outercourse (i.e., foreplay, heavy petting); receive oral sex, and perform oral sex. Participants reported whether they engaged in each sexual behavior in the past year (yes/no).

\subsubsection{Health Indicators}

Three measures assessed participants' health status. First, their number of selfreported chronic conditions selected from a list of 12 conditions (e.g., hypertension, diabetes, arthritis, and cancer). Second, a single self-report item on general health status (i.e., "poor" to "excellent") [15]. Third, self-reported depressive symptoms over the past seven days on 
an 11-item version of the Center for Epidemiologic Studies Depression Scale (CES-D); with higher scores indicating higher depressive symptomology [16].

\subsubsection{Sexual Health and Perceptions}

Participants self-reported their lifetime number of sexual partners before rating their degree of agreement with the statement "pleasurable sex is necessary to maintain a relationship." Responses from this 4-category item were dichotomized (disagree/agree).

\subsubsection{Communication}

Participants reported how often they felt they could open up to partners about worries and concerns. Based on the frequency distribution, responses to this three-category item were dichotomized into "hardly ever/sometimes" and "often."

\subsubsection{Socio-Demographics}

Personal characteristics of interest included age groups (i.e., 60-64 years, 65-69 years, 70-74 years, 75+ years); race/ethnicity (i.e., non-Hispanic White, African American, Hispanic); and educational attainment (i.e., less than high school, high school graduate, vocational/associate's/some college, bachelor's degree or more).

\subsection{Statistical Analyses}

All statistical analyses were performed using SPSS (version 25.0). Frequencies and descriptive statistics were calculated. Pearson's chi-square tests were performed to assess independence between each dependent variable and categorized independent variables. Independent Samples t Tests were used to evaluate mean differences for continuous variables. A series of four binary logistic regression models were fitted to identify factors associated with engaging in each sexual behavior in the past year (i.e., not performing the behavior served as the referent group). Odds ratios, confidence intervals, and model fit statistics are reported. $p$-values $<0.05$ indicate statistical significance.

\section{Results}

\subsection{Participant Characteristics}

Participants' average age was 68.98 years $( \pm 6.80)$, with $24.9 \%$ being age $\geq 75$ years. Approximately $82 \%$ of participants were non-Hispanic White, $8.5 \%$ were African American, and 9.8\% were Hispanic. In terms of education, $16.5 \%$ had less than a high school education; $31.7 \%$ had a high school diploma; $33.4 \%$ had a vocational certificate, associate's degree, or some college; and $18.4 \%$ had a bachelor's degree or higher. On average, participants self-reported $1.67( \pm 1.25)$ chronic conditions. Approximately $65 \%$ of participants agreed that pleasurable sex was necessary for relationship maintenance, and $75.1 \%$ reported they could open up to their partners about their worries and concerns often. Participants reported an average of $2.86( \pm 4.88)$ lifetime sexual partners. In the past year, $53.6 \%$ reported vaginal intercourse; $56.0 \%$ reported outercourse; $21.7 \%$ reported receiving oral sex; and 20.6\% reported performing oral sex. Overall, participants reported engaging in $1.52( \pm 1.52)$ of the four sexual behaviors in the past year, with $43.6 \%$ engaging in none of the sexual behaviors. Almost one in five women (17.8\%) reported engaging in all four behaviors.

\subsection{Factors Associated with Sexual Behaviors}

As shown in Table 1, findings from the four binary logistic regression models revealed common and unique factors associated with sexual behaviors. Model fit statistics were strong, with Nagelkerke $R^{2}$ values ranging from 0.220 to 0.291 . Across all four models, women $\geq 70$ years were less likely to report engaging in these sexual behaviors, compared to their younger counterparts ages 60-64 years. Similarly, across all models, women who agreed that pleasurable sex was necessary to maintain relationships were more likely to report engaging in these sexual behaviors. Women who opened up to their partners about their worries and concerns often were more likely to report vaginal intercourse, outercourse, and performing oral sex in the past year, respectively. 
Table 1. Logistic Regression for Engaging in Sexual Behaviors Within the Past Year.

\begin{tabular}{|c|c|c|c|c|c|c|c|c|c|c|c|c|c|c|c|c|}
\hline & \multicolumn{4}{|c|}{ Vaginal Intercourse } & \multicolumn{4}{|c|}{ Outercourse } & \multicolumn{4}{|c|}{ Receive Oral Sex } & \multicolumn{4}{|c|}{ Perform Oral Sex } \\
\hline & \multicolumn{6}{|c|}{$95 \%$ CI } & \multicolumn{2}{|c|}{$95 \% \mathrm{CI}$} & \multicolumn{6}{|c|}{$95 \%$ CI } & \multicolumn{2}{|c|}{$95 \% \mathrm{CI}$} \\
\hline & OR & $p$ & Lower & Upper & OR & $p$ & Lower & Upper & OR & $p$ & Lower & Upper & OR & $p$ & Lower & Upper \\
\hline Age: $60-64$ Years & 1.00 & - & - & - & 1.00 & - & - & - & 1.00 & - & - & - & 1.00 & - & - & - \\
\hline Age: $70-74$ Years & 0.35 & 0.001 & 0.19 & 0.64 & 0.37 & 0.001 & 0.20 & 0.68 & 0.35 & 0.008 & 0.16 & 0.76 & 0.31 & 0.005 & 0.14 & 0.70 \\
\hline Age: $75+$ Years & 0.20 & $<0.001$ & 0.12 & 0.36 & 0.23 & $<0.001$ & 0.13 & 0.41 & 0.22 & $<0.001$ & 0.10 & 0.47 & 0.19 & $<0.001$ & 0.08 & 0.43 \\
\hline $\begin{array}{l}\text { Race/Ethnicity: Non-Hispanic } \\
\text { White }\end{array}$ & 1.00 & - & - & - & 1.00 & - & - & - & 1.00 & - & - & - & 1.00 & - & - & - \\
\hline $\begin{array}{l}\text { Race/Ethnicity: African } \\
\text { American }\end{array}$ & 1.40 & 0.38 & 0.66 & 2.98 & 1.27 & 0.54 & 0.60 & 2.70 & 0.12 & 0.005 & 0.03 & 0.53 & 0.13 & 0.008 & 0.03 & 0.58 \\
\hline Race/Ethnicity: Hispanic & 1.13 & 0.74 & 0.55 & 2.32 & 1.19 & 0.64 & 0.58 & 2.46 & 0.68 & 0.44 & 0.25 & 1.83 & 0.93 & 0.88 & 0.35 & 2.45 \\
\hline Education: Less than High School & 1.00 & - & - & - & 1.00 & - & - & - & 1.00 & - & - & - & 1.00 & - & - & - \\
\hline Education: High School Graduate & 0.86 & 0.65 & 0.45 & 1.65 & 0.88 & 0.69 & 0.46 & 1.67 & 2.06 & 0.17 & 0.74 & 5.74 & 3.38 & 0.04 & 1.04 & 10.97 \\
\hline $\begin{array}{l}\text { Education: Some } \\
\text { College/Vocational/Associates }\end{array}$ & 0.80 & 0.51 & 0.41 & 1.56 & 0.87 & 0.68 & 0.45 & 1.69 & 2.17 & 0.13 & 0.79 & 5.93 & 3.24 & 0.05 & 1.01 & 10.39 \\
\hline $\begin{array}{l}\text { Education: College Graduate or } \\
\text { More }\end{array}$ & 0.94 & 0.86 & 0.43 & 2.03 & 1.27 & 0.56 & 0.58 & 2.77 & 4.43 & 0.006 & 1.53 & 12.85 & 6.10 & $<0.001$ & 1.81 & 20.54 \\
\hline CES-D Depression Scale & 0.95 & 0.02 & 0.90 & 0.99 & 0.95 & 0.04 & 0.91 & 1.00 & 0.97 & 0.36 & 0.91 & 1.03 & 0.97 & 0.34 & 0.91 & 1.03 \\
\hline Total Lifetime Sex Partners & 1.00 & 0.84 & 0.95 & 1.04 & 1.01 & 0.82 & 0.96 & 1.06 & 1.05 & 0.10 & 0.99 & 1.10 & 1.06 & 0.05 & 1.00 & 1.12 \\
\hline $\begin{array}{l}\text { Pleasurable Sex Necessary to } \\
\text { Maintain Relationship: Disagree }\end{array}$ & 1.00 & - & - & - & 1.00 & - & - & - & 1.00 & - & - & - & 1.00 & - & - & - \\
\hline $\begin{array}{l}\text { Pleasurable Sex Necessary to } \\
\text { Maintain Relationship: Agree }\end{array}$ & 2.08 & 0.001 & 1.36 & 3.19 & 2.34 & $<0.001$ & 1.52 & 3.58 & 2.81 & $<0.001$ & 1.59 & 4.97 & 3.04 & $<0.001$ & 1.67 & 5.52 \\
\hline $\begin{array}{l}\text { Frequency Open Up to Partner } \\
\text { about Worries: Hardly } \\
\text { Ever/Sometimes }\end{array}$ & 1.00 & - & - & - & 1.00 & - & - & - & 1.00 & - & - & - & 1.00 & - & - & - \\
\hline \multirow[t]{2}{*}{$\begin{array}{l}\text { Frequency Open Up to Partner } \\
\text { about Worries: Often }\end{array}$} & 2.14 & 0.002 & 1.31 & 3.49 & 2.30 & 0.001 & 1.41 & 3.75 & 1.45 & 0.26 & 0.77 & 2.73 & 2.24 & 0.03 & 1.11 & 4.53 \\
\hline & \multicolumn{4}{|c|}{ Nagelkerke $R^{2}=0.220$} & \multicolumn{4}{|c|}{ Nagelkerke $R^{2}=0.224$} & \multicolumn{4}{|c|}{ Nagelkerke $R^{2}=0.257$} & \multicolumn{4}{|c|}{ Nagelkerke $R^{2}=0.291$} \\
\hline
\end{tabular}


For every unit increase in self-reported depressive symptomology, the odds of engaging in vaginal intercourse and outercourse decreased significantly. Regarding oral sex, women with high school diplomas and higher educational attainment were more likely to perform oral sex in the past year, compared to those with less than high school education. Women with college degrees and higher educational attainment were more likely to receive oral sex in the past year, compared to those with less than high school education. For each additional lifetime sexual partner reported, the odds of reporting having performed oral sex in the past year increased. Compared to non-Hispanic White women, African American women were less likely to report receiving or giving oral sex in the past year.

\section{Discussion}

This study described factors associated with four sexual behaviors among mar$\mathrm{ried} /$ partnered women ages $\geq 60$ years in the U.S. More than half of women in this sample engaged in both outercourse and intercourse in the past year. Sexual behaviors varied by certain sociodemographic factors such as educational attainment and race/ethnicity. For example, women with a high school degree or higher were significantly more likely to perform oral sex, and those with at least college degrees were more likely to receive and perform oral sex. These findings are consistent with literature related to education attainment and sexual mores and practices [17]. In contrast, African American women in the sample were significantly less likely to receive or perform oral sex in the past year, which is consistent with existing literature describing cultural and social norms related to these sexual behaviors in this population [7].

Consistent with the Basson [13] model, women with depressive symptoms were less likely to engage in these two sexual behaviors. Depression is known to impair libido, arousal, and sexual functioning, resulting in reduced desire and pleasure [3]; decreased initiation of sexual activity; and increased risk of sexual pain [18]. Interestingly, in our sample, depressive symptoms were not associated with oral sex behaviors. This finding remains consistent with the Basson model, in that when women have stronger beliefs and feelings of intimacy with their partners, these cognitive and psychological connections may reinforce trust and foster enhanced communication, such that women may be more receptive to performing sexual behaviors [13].

Similarly, women who agreed that pleasurable sex was necessary to maintain a relationship also engaged in more sexual behaviors. While this finding appears logical considering our sample of married/partnered older women, it may suggest that women's desires for connection and intimacy may reinforce relationship maintenance behaviors including care for their partners' cognitive, affective, and sexual wellbeing. This result is consistent with previous literature on pleasure and sexual intimacy in later life [8,9]. Additionally, while most women reported opening up to their partners about their worries and concerns, those who did often were more likely to engage in a greater number of sexual behaviors in the past year. The association between general couple communication about worries and concerns and greater participation in sexual behaviors may be explained by the fact that communication between partners, in particular about sexual matters, can enhance feelings of intimacy and trust [19]; contribute to achieving sexual goals [20]; and enhance overall sexual well-being [21].

\section{Limitations}

Study limitations include the cross-sectional nature of the data, the small sample size of 461 women, and the limited representation of older women of color. This sample was limited to only the U.S.; therefore, findings may not be generalizable to other populations or nations. Further, this study only included married and partnered women, which highlights a substantial proportion of the women in this older age group. However, associations observed in this sample may differ among women who are divorced, never married, or widowed. Future studies among larger and more diverse samples are needed to examine the roles of intimacy and communication on sexual behaviors. 


\section{Conclusions}

The objective of this study was to assess factors associated with sexual behaviors in partnered or married White, African American, and Hispanic women ages 60 years and older. Our findings suggest that women who agreed that pleasurable sex was important to maintain a relationship and those who opened up to their partner reported greater frequency of sexual behavior. This study contributes to the literature by providing additional psychological and emotional factors that influence the intimate experiences and sexual behaviors of older married/partnered women residing in the U.S. Future research should explore the potential reciprocal influence of cognitive, affective, and relational factors on sexual behaviors, relationship quality, and sexual satisfaction.

Author Contributions: Conceptualization, C.D.B., H.H.G. and M.L.S.; Data curation, C.D.B.; Formal analysis, C.D.B. and H.H.G.; Writing-original draft, C.D.B., H.H.G., A.B. and M.L.S.; Writingreview \& editing, C.D.B., H.H.G., A.B. and M.L.S. All authors contributed significantly to this work. All authors have read and agreed to the published version of the manuscript.

Funding: The authors have no funding to report.

Institutional Review Board Statement: This study was determined to be non-human subjects research by the Texas A\&M University Institutional Review Board (\#20100417).

Informed Consent Statement: Not applicable.

Data Availability Statement: Not applicable.

Conflicts of Interest: The authors declare no conflict of interest.

\section{References}

1. Herbenick, D.; Reece, M.; Schick, V.; Sanders, S.A.; Dodge, B.; Fortenberry, J.D. Sexual Behavior in the United States: Results from a National Probability Sample of Men and Women Ages 14-94. J. Sex. Med. 2010, 7, 255-265. [CrossRef] [PubMed]

2. Lindau, S.T.; Gavrilova, N. Sex, health, and years of sexually active life gained due to good health: Evidence from two US population based cross sectional surveys of ageing. BMJ 2010, 340, c810. [CrossRef] [PubMed]

3. Ussher, J.M.; Perz, J.; Parton, C. Sex and the menopausal woman: A critical review and analysis. Fem. Psychol. 2015, 25, 449-468. [CrossRef]

4. $\quad$ Bergeron, C.D.; Goltz, H.H.; Szucs, L.E.; Reyes, J.V.; Wilson, K.L.; Ory, M.G.; Smith, M.L. Exploring sexual behaviors and health communication among older women. Health Care Women Int. 2017, 38, 1356-1372. [CrossRef] [PubMed]

5. Liu, H.; Shen, S.; Hsieh, N. A National Dyadic Study of Oral Sex, Relationship Quality, and Well-Being among Older Couples. J. Gerontol. B Psychol. Sci. Soc. Sci. 2019, 74, 298-308. [CrossRef] [PubMed]

6. $\quad$ Dodge, B.; Reece, M.; Herbenick, D.; Schick, V.; Sanders, S.A.; Fortenberry, J.D. Sexual Health Among U.S. Black and Hispanic Men and Women: A Nationally Representative Study. J. Sex. Med. 2010, 7, 330-345. [CrossRef] [PubMed]

7. Townes, A.; Thorpe, S.; Parmer, T.; Wright, B.; Herbenick, D. Partnered Sexual Behaviors, Pleasure, and Orgasms at Last Sexual Encounter: Findings from a U.S. Probability Sample of Black Women Ages 18 to 92 Years. J. Sex Marital Ther. 2021, 47, $353-367$. [CrossRef] [PubMed]

8. Gewirtz-Meydan, A.; Ayalon, L. Why Do Older Adults Have Sex? Approach and Avoidance Sexual Motives Among Older Women and Men. J. Sex Res. 2019, 56, 870-881. [CrossRef] [PubMed]

9. Ševčíková, A.; Sedláková, T. The Role of Sexual Activity from the Perspective of Older Adults: A Qualitative Study. Arch. Sex. Behav. 2020, 49, 969-981. [CrossRef] [PubMed]

10. Shenbakam, N.; Sathyamurthi, K. Happily ever after: Factors influencing emotional intimacy of elderly couple. In Elderly Wellbeing and Intergenerational Bonding; Sathuamurthi, K., Ed.; Today Publication: Chennai, India, 2019; pp. 38-44.

11. Yoo, H.; Bartle-Haring, S.; Day, R.D.; Gangamma, R. Couple Communication, Emotional and Sexual Intimacy, and Relationship Satisfaction. J. Sex Marital Ther. 2014, 40, 275-293. [CrossRef] [PubMed]

12. Anderson, R.M. Positive sexuality and its impact on overall well-being. Bundesgesundheitsblatt -Gesundh. -Gesundh. 2013, 56, 208-214. [CrossRef] [PubMed]

13. Basson, R. The Female Sexual Response: A Different Model. J. Sex Marital Ther. 2000, 26, 51-65. [CrossRef] [PubMed]

14. Suzman, R. The National Social Life, Health, and Aging Project: An Introduction. J. Gerontol. B Psychol. Sci. Soc. Sci. 2009, 64B (Suppl. 1), i5-i11. [CrossRef] [PubMed]

15. Centers for Disease Control and Prevention. Measuring Healthy Days; CDC: Atlanta, GA, USA, 2020.

16. Andresen, E.M.; Malmgren, J.A.; Carter, W.B.; Patrick, D.L. Screening for Depression in Well Older Adults: Evaluation of a Short Form of the CES-D. Am. J. Prev. Med. 1994, 10, 77-84. [CrossRef] 
17. Gómez Melasio, D.A.; Onofre Rodríguez, D.J.; Benavides Torres, R.A.; Trujillo Hernández, P.E. A Systematic Review of Individual, Psychological and Sociocultural Factors Associated with Safe and Risky Sexual Behavior in Older Adults. Am. J. Sex. Educ. 2021, 16, 415-434.

18. Kalmbach, D.A.; Ciesla, J.A.; Janata, J.W.; Kingsberg, S.A. Specificity of Anhedonic Depression and Anxious Arousal with Sexual Problems Among Sexually Healthy Young Adults. J. Sex. Med. 2012, 9, 505-513. [CrossRef] [PubMed]

19. MacNeil, S.; Byers, E.S. Role of Sexual Self-Disclosure in the Sexual Satisfaction of Long-Term Heterosexual Couples. J. Sex Res. 2009, 46, 3-14. [CrossRef] [PubMed]

20. Cupach, W.R.; Metts, S. Sexuality and communication in close relationships. In Sexuality in Close Relationships; McKinney, K., Sprecher, S., Eds.; Erlbaum: Hillsdale, NJ, USA, 1991; pp. 93-106.

21. Merwin, K.E.; Rosen, N.O. Perceived Partner Responsiveness Moderates the Associations Between Sexual Talk and Sexual and Relationship Well-Being in Individuals in Long-Term Relationships. J. Sex Res. 2020, 57, 351-364. [CrossRef] [PubMed] 